\title{
Novas espécies de Acanthoderini, Onciderini e Pteropliini (Coleoptera: Cerambycidae: Lamiinae) do Brasil e da Bolívia
}

\author{
Maria Helena M. GALILEO ${ }^{1,3}$ \& Ubirajara R. MARTINS ${ }^{2,3}$ \\ RESUMO \\ Novas espécies são descritas: em Acanthoderini - Psapharochrus inaequalis sp. nov. e Psapharochrus irumus sp. nov. de Santa \\ Cruz, Bolívia; Psapharochrus rondonensis sp. nov e Punctozotroctes tuberculatus sp. nov. de Rondônia, Brasil; Meridiotroctes \\ truncata sp. nov. da Bahia, Brasil; em Pteropliini - Rhaphiptera apeara sp. nov. da Bahia (Brasil) and Ataxia parva sp. nov. da \\ Paraíba (Brasil); em Onciderini - Oncideres disiunctus sp. nov. do Amazonas (Brasil).
}

PALAVRAS-CHAVE: Coleoptera; Taxonomia; Neotropical.

\section{New species of Acanthoderini, Onciderini and Pteropliini (Coleoptera: Cerambycidae: Lamiinae) from Brazil and Bolivia}

\section{ABSTRACT}

New species are described: in Acanthoderini - Psapharochrus inaequalis sp. nov. and Psapharochrus irumus sp. nov. from Santa Cruz, Bolívia; Psapharochrus rondonensis sp. nov and Punctozotroctes tuberculatus sp. nov. from Rondônia, Brazil; Meridiotroctes truncata sp. nov. from Bahia, Brazil; in Pteropliini - Rhaphiptera apeara sp. nov. from Bahia (Brazil) and Ataxia parva sp. nov. from Paraíba (Brazil); in Onciderini - Oncideres disiunctus sp. nov. from Amazonas (Brazil).

KEYWORDS: Coleoptera; Taxonomy; Neotropical.

${ }_{1}^{1}$ Museu de Ciências Naturais, Fundação Zoobotânica do Rio Grande do Sul. Caixa Postal 1188, 90001-970, Porto Alegre, RS, Brasil. E-mail: galileo@fzb.rs.gov.br

2 Museu de Zoologia, Universidade de São Paulo. Caixa Postal 42494, 04218-970, São Paulo, SP, Brasil. E-mail: urmsouza@usp.br

3 Pesquisador do CNPq. 


\section{INTRODUÇÃO}

O estudo de material recebido para identificação do Instituto Nacional de Pesquisas da Amazônia, Manaus, da Universidade Estadual de Feira de Santana, Feira de Santana, Bahia e do American Coleoptera Museum, San Antonio, Texas, oportunizou detectar novas espécies de Lamiinae. Em Acanthoderini, acrescentam-se três espécies: uma de Psapharochrus Thomson, 1864, uma em Meridiotroctes Martins \& Galileo, 2007 e uma para Punctozotroctes Tavakilian \& Néouze, 2007.

Machado \& Monné (2009) apresentaram uma sinopse de Meriodiotroctes e descreveram a segunda espécie; ambas ocorrem na Mata Atlântica. Tavakilian \& Néouze (2007) propuseram Punctozotroctes com cinco espécies da Guiana Francesa. Martins \& Galileo (2007) acrescentaram outras duas espécies, uma da Bolívia e outra do Brasil (Pernambuco) e Martins et al. (2009) adicionaram mais uma espécie ocorrente no Maranhão (Brasil). Psapharochrus apresenta, até o momento, 86 espécies com ampla distribuição do México à Argentina. Descrevemos duas espécies, uma é semelhante a $P$. corticarius (Tippmann, 1960) e outra com padrão de colorido particular e com dois tubérculos pronotais, caráter pouco frequente entre os Psapharochrus.

Em Pteropliini, tribo revista por Breuning (1961), adiciona-se mais duas espécies, respectivamente, nos gêneros Ataxia Haldeman, 1847 e Rhaphiptera Audinet-Serville, 1835. Em Ataxia, contam-se 39 espécies distribuídas dos Estados Unidos, Antilhas, América Central e na América do Sul da Colômbia à Argentina. O gênero Rhaphiptera reúne 25 espécies com distribuiçáo predominante na América do Sul. As espécies de Rhaphiptera da Guiana Francesa foram revistas por Tavakilian et al. (2007) com a proposição de três espécies novas.

No gênero Oncideres Lacordaire, 1830 (Onciderini) que conta com 116 espécies, descreve-se uma espécie semelhante a O. pretiosa Martins \& Galileo, 1990 e a O. fulvoguttata Dillon \& Dillon, 1946.

As abreviaturas no texto correspondem às coleçôes: Instituto Nacional Museo Noel Kempff Mercado, Santa Cruz (MNKM); Museu de Zoologia, Universidade de São Paulo, São Paulo (MZSP); Universidade Estadual de Feira de Santana, Feira de Santana (UEFS).

\section{ACANTHODERINI}

\section{Meridiotroctes truncata sp. nov.}

Figura 8

Etimologia. Latim, truncata $=$ truncado, o ápice terminado por linha transversal; alusivo às extremidades elitrais.
Descriçáo. Tegumento castanho-escuro. Fronte com pubescência castanho-amarelada; fina e esparsamente pontuada. Vértice com pubescência acastanhada, sem pontos. Olhos inteiros; lobos oculares superiores com sete fileiras de omatídios, distância entre os lobos igual a largura de um lobo. Lobos oculares inferiores com o quádruplo do comprimento das genas. Escapo coberto com pubescência esbranquiçada. Flagelômeros castanhoamarelados com a regiâo apical preta, gradualmente mais larga até o antenômero X.

Protórax com espinho lateral aguçado, não voltado para trás. Partes laterais do protórax grosseiramente pontuadas e com pubescência esbranquiçada. Pronoto com dois tubérculos anteriores e um central, projetados e dois tubérculos basais menos pronunciados; superfície pronotal com pontos profundos numerosos e pubescência castanhoamarelada.

Élitros com pubescência de fundo acastanhada, mesclada de amarelado; pubescência branca junto a sutura no terço central e expandida para o dorso com alguns pontos contrastantes no início do terço apical. Pontuaçáo elitral moderadamente abundante, os pontos com pelos brancos, curtos e rijos (25x). Extremidades elitrais subarredondadas.

Mesocoxas sem tubérculos. Fêmures com tegumento castanho-escuro na clava e avermelhado no pedúnculo. Profêmures cobertos por pubescência branca. Meso- e metafêmures cobertos por pubescência branca aparentemente mais esparsa. Tíbias castanho-avermelhadas com pubescência esbranquiçada na base, no centro e na regiáo apical. Metatarsômeros com tegumento avermelhado e pubescência esbranquiçada.

Esternos torácicos e urosternitos castanho-avermelhados, revestidos por pubescência branca.

Dimensões em mm. Comprimento total, 9,7; comprimento do protórax, 2,0; maior largura do protórax, 2,8; comprimento do élitro, 7,0; largura umeral, 3,2.

Material-tipo. Holótipo macho, BRASIL, Babia: Senhor do Bonfim (UTM: 367691/8850126), 6.X.2005, D. Almeida \& E. Alvim col. (UEFS).

Discussão. Meridiotroctes truncata difere de M. meridionalis Martins \& Galileo, 2007 pelos lobos oculares superiores e inferiores desenvolvidos; pelos tubérculos pronotais apenas projetados e pelos ápices dos élitros truncados. Além disso, o padrão de colorido é distinto. Em M. meridionalis, os lobos oculares superiores são tão distantes entre si quanto a largura de um lobo, os lobos inferiores sáo táo longos quanto as genas, o pronoto tem tubérculos desenvolvidos e os ápices dos élitros são arredondados em conjunto. 


\section{Punctozotroctes tuberculatus sp. nov.}

Figura 4

Etimologia. Latim, tuberculatus = dotado de tubérculos; alusivo às mesocoxas dotadas de tubérculo.

Descrição. Cabeça revestida por pubescência predominantemente amarelada com uma mancha preta a cada lado do vértice. Fronte com pontos grossos. Olhos inteiros; lobos oculares superiores com sete fileiras de omatídios, táo distantes entre si quanto o dobro da largura de um lobo. Lobos oculares inferiores com o dobro do comprimento das genas. Antenas avermelhadas, não atingem o ápice do élitro.

Pronoto com cinco tubérculos: dois látero-anteriores, projetados; um central e dois látero-basais, pouco projetados. Centro do pronoto com pubescência predominantemente alaranjada; nos lados, com pubescência mais esbranquiçada. Pontuaçáo no centro do pronoto constituída por pontos grossos, moderadamente densos; nos lados do pronoto, pontos profundos e mais densos.

Élitros com pubescência de fundo amarelada e faixas irregulares mais ou menos transversais, irregulares, de pubescência preta; região central com escassa pubescência branca ao longo da sutura que emite para cada lado um ramo curto. Pontuação elitral densa, os pontos com pelos brancos, curtos, rijos (25x). Extremidades elitrais arredondadas em conjunto.

Lado interno das mesocoxas com pequeno tubérculo (32x) no nível do meio. Fêmures com pubescência esbranquiçada. Tíbias com pubescência esbranquiçada e dois anéis pretos. Tarsos com tegumento avermelhado cobertos por pubescência esbranquiçada.

Face ventral com pubescência esbranquiçada. Lados do metasterno liso.

Dimensôes em mm. Comprimento total, 9,5; comprimento do protórax, 2,0; maior largura do protórax, 3,0; comprimento do élitro, 6,7; largura umeral, 3,8.

Material-tipo. Holótipo macho, BRASIL, Rondônia: Santo Antonio (Rio Madeira, margem esquerda, interior), 11.VI.2004, armadilha luminosa (MZSP).

Discussão. Punctozotroctes tuberculatus assemelha-se a P. wappesi Tavakilian \& Néouze, 2007, descrita da Guiana Francesa. Difere pela extensão da área branca dos élitros, pelas extremidades elitrais arredondadas e pela maior quantidade de faixas pretas nos élitros. Tavakilian \& Néouze (2007) não mencionaram o tubérculo no lado interno das mesocoxas como em Punctozotroctes tuberculatus o que poderia ser mais um caráter diferencial.

\section{Psapharochrus inaequalis sp. nov.}

Figura 3

Etimologia. Latim, inaequalis $=$ diferente.

Descrição. Tegumento preto exceto nos protarsômeros III-V, meso- e metatarsômeros I e III-V, castanho-amarelado. Fronte revestida por pubescência branca com poucos pontos contrastantes, pretos. Olhos divididos. Lobos oculares inferiores mais curtos do que as genas. Vértice com pubescência mais amarelada e alguns pontos profundos e contrastantes. Escapo com pubescência branca, esparsa em toda a superfície. Lado interno dos antenômeros III, IV e V com concentração de pelos pretos. Antenômero III com pubescência branca, rala, principalmente na metade basal. Antenômero IV, na metade basal, amarelado e com pubescência branca; $V$ e seguintes com anel basal amarelado e pubescência branca. Antenas atingem a extremidade do élitro na ponta do antenômero X.

Espinho lateral do protórax aguçado. Pronoto com quilha central e dois tubérculos anterolaterais, longitudinais e pouco projetados. Partes laterais do protórax e pronoto com escassa pubescência amarelada, entremeada por pontos contrastantes pretos. Prosterno com pubescência amarelada.

Élitros com pubescência predominante amarelada entremeada por pontos contrastantes; manchas de pubescência branca: nos lados da metade anterior, oblíqua da crista centro basal até a margem; pequena, no terço anterior junto à sutura; duas dorsais, quase no meio, irregulares; faixa no quarto apical ligeiramente oblíqua em sentido ascendente da sutura para a margem. Cristas centro-basais dos élitros, curtas e encimadas por tubérculos. Pontuaçấo elitral com pontos ásperos na base e grandes no centro região dorsal. Ápices dos élitros com espinho externo.

Pubescência amarelada dos fêmures entremeada por abundantes pontos contrastantes. Protíbias pretas com estreito anel basal de pelos brancos. Meso- e metatíbias tíbias amareladas no terço central.

Lados do metasterno cobertos por pubescência amarelada entremeada por pontos contrastantes. Urosternitos mais avermelhados com pubescência amarelada mais concentrada nos lados.

Dimensōes em mm. Comprimento total, 9,0; comprimento do protórax, 2,0; maior largura do protórax, 3,0; comprimento do élitro, 6,7; largura umeral, 4,0.

Material-tipo. Holótipo macho, BOLÍVIA, Santa Cruz: Chaco "above" Achira, 1730 m, 22-25.I.2007, Wappes \& Lingafelter col. (MNKM).

Discussão. Psapharochrus inaequalis é semelhante a $P$. corticarius (Tippmann, 1960), mas distingue-se pela ausência de área de pubescência branca no meio do pronoto; pela 
presença de faixa de pubescência branca no quarto apical dos élitros; pela pontuaçáo contrastante dos fêmures e pelos protarsômeros III-V amarelados.

\section{Psapharochrus irumus sp. nov.}

Figura 6

Etimologia. Tupi, irumo $=\mathrm{com}$; alusivo ao pronoto com tubérculos.

Descrição. Tegumento preto. Cabeça com pubescência esbranquiçada muito esparsa. Alguns pontos profundos entre a base dos tubérculos anteníferos e os lobos oculares superiores. Olhos finamente granulados, divididos. Escapo preto, esparsamente pubescente. Pedicelo e antenômero III pretos; IV preto com dois anéis de tegumento amarelado: um na base e outro no meio. Antenômeros $\mathrm{V}$ a X pretos e amarelados nas bases. Antenômeros basais com pelos no lado interno.

Protórax coberto por pubescência branco-amarelada, muito esparsa. Espinho lateral do protórax único e acuminado. Pronoto com três tubérculos: dois látero-anteriores, bem desenvolvidos e um central, menos projetado. Partes laterais do protórax com pontuaçấo profunda, moderadamente densa. Prosterno com tegumento liso e brilhante. Escutelo com pubescência esparsa e pouco aparente.

Élitros com pubescência acastanhada entremeada por rara pilosidade branca. Em cada élitro, manchas de pubescência branca, densa: a frente do meio, faixa de contornos irregulares, oblíqua em sentido descendente da margem para a sutura, fundida à margem e distante da sutura; outra faixa oblíqua, a frente dessa, mais estreita, atinge a sutura e a declividade lateral; terço apical com pequena mancha dorsal. Entre as duas faixas brancas, manchas de pubescência acastanhada adensada. Crista centro-basal granulosa e pouco elevada, seguida por carena até o terço apical dos élitros. Extremidades elitrais levemente emarginadas e projetadas no ângulo externo. Pontuação densa na metade basal dos élitros e pontos contrastantes no interior das faixas brancas.

Face ventral do corpo com pubescência muito escassa. Fêmures com escassa pubescência acastanhada. Tíbias com anel central de tegumento amarelado. Protíbias dilatadas na metade apical. Protarsos com os tarsômeros III a V amarelados. Meso- e metatarsômeros avermelhados com o tarsômero II preto.

Dimensóes em mm. Comprimento total, 10,3; comprimento do protórax, 2,1; maior largura do protórax, 3,9; comprimento do élitro, 7,3; largura umeral, 4,5.

Material-tipo. Holótipo macho, BOLÍVIA, Santa Cruz: Comarapa (Caballevo) 18.IV.1992, J. L. Avaneyo col. (MNKM).
Discussão. Psapharochrus irumus sp. nov. tem padrão de colorido particular que a distingue de todas as outras espécies. A presença de dois tubérculos pronotais também é caráter pouco frequente entre os Psapharochrus.

\section{Psapharochrus rondonensis sp. nov.}

Figura 1

Etimologia. O nome específico é alusivo ao estado de Rondônia, Brasil.

Descrição. Tegumento preto. Palpos maxilares muito alongados. Cabeça revestida por pubescência castanhoamarelada. Fronte com pontos pequenos. Olhos náo divididos. Lobos oculares superiores com dez fileiras de omatídios; aproximadamente tấo afastados quanto a largura de um lobo. Lobos oculares inferiores com o dobro do comprimento das genas. Pontos profundos e abundantes entre os lobos oculares e entre os tubérculos anteníferos. Antenas atingem o ápice dos élitros na ponta do antenômero VIII (onde as antenas estáo quebradas). Base dos flagelômeros com anel de pubescência branco-amarelada.

Protórax com larga área central, longitudinal de pubescência amarelo-acastanhada; lados com pubescência acastanhada. Pronoto com dois tubérculos látero-anteriores e um central, estreito, longitudinal. Partes laterais do protórax com pubescência uniforme, castanho-amarelada e alguns pontos profundos, contrastantes.

Élitros com pubescência predominante castanhoamarelada. Cada élitro com três manchas pretas de contorno irregular: a primeira no quarto basal, a segunda, maior, atrás do meio e a terceira, antiapical; manchas pretas ao longo da sutura. Pontuaçáo elitral abundante e contrastante. Extremidades dos élitros obliquamente truncadas e desarmadas.

Parte inferior do corpo coberta por pubescência amareloacastanhada. Fêmures cobertos por pubescência amareloacastanhadas. Protíbias pretas na face externa; pubescência esbranquiçada no lado interno. Meso- e metatíbias com anéis de pubescência branca na base e no terço apical. Tarsos cobertos por pubescência amarelada; metatarsômero I mais longo do que o II+III em conjunto.

Dimensôes em mm. Comprimento total, 20,5; comprimento do protórax, 3,3; maior largura do protórax, 6,2; comprimento do élitro, 15,3; largura umeral, 7,6.

Material-tipo. Holótipo fêmea, BRASIL, Rondônia: Jirau (Rio Madeira, margem direita, interior), 5.IX.2004, sem nome do coletor, armadilha luminosa (MZSP).

Discussão. Psapharochrus rondonensis assemelha-se a $P$. longitarsis (Bates, 1880) por apresentar os metatarsômeros com a mesma proporção. Difere pelos ápices dos élitros sem espículo no lado externo, pela ausência de crista centro-basal; pelos pontos elitrais na metade basal, não ásperos; pelas 
metatíbias com dois anéis brancos e pelo colorido geral. Em $P$. longitarsis os ápices elitrais são transversalmente truncados com espinho externo; a crista centro-basal dos élitros é granulosa; os pontos da metade basal dos élitros são bem projetados e o colorido geral apresenta, principalmente na metade apical, algumas pequenas manchas de pubescência amarelada e as metatíbias têm três anéis brancos.

\section{PTEROPLIINI}

\section{Rhaphiptera apeara sp. nov.}

Figura 5

Etimologia. Tupi, apeara = superfície; alusivo a dos élitros, cobertas por pubescência uniforme e com pontuação inaparente.

Descrição. Tegumento preto-avermelhado a preto. Pubescência cinza-amarelada, uniforme. Cabeça com pubescência amarelada ao redor dos olhos. Fronte finamente pontuada. Vértice com pontos principalmente entre os lobos oculares superiores. Lobos oculares superiores com oito fileiras de omatídios; pouco mais distantes entre si do que a largura de um lobo. Antenas atingem o ápice dos élitros na metade do antenômero XI. Antenas castanho-avermelhadas e ápice dos antenômeros gradualmente mais escurecido em direção aos apicais; pubescência acinzentada.

Protórax com espinhos laterais desenvolvidos e rombos. Pronoto com tubérculos látero-anteriores glabros, projetados e arredondados no topo. Pontuaçáo pronotal fina e esparsa. Partes laterais do protórax sem pontos. Escutelo coberto por pubescência amarelo-esbranquiçada.

Élitros com pontuação pouco aparente sob a pilosidade; faixa lateral de pubescência esbranquiçada. Extremidades elitrais transversalmente truncadas.

Face ventral com pubescência mais concentrada nos mesepisternos, mesepimeros, metepisternos e lados dos urosternitos. Pernas revestidas por pubescência amarelada. Lado interno das protíbias com espinho e pelos abundantes e eretos.

Dimensôes em mm. Comprimento total, 19,4; comprimento do protórax, 3,7; maior largura do protórax, 5,3; comprimento do élitro, 13,7; largura umeral, 5,5.

Material-tipo. Holótipo macho, BRASIL, Bahia: Ituberá ( Michellin), 17.XI.2007, João, Zafir \& Daniela col. MZUEFS \#33894 (UEFS).

Discussão. Rhaphiptera apeara sp. nov. assemelha-se a $R$. melzeri Fragoso \& Monné, 1984 pela pubescência unicolor, cinza-amarelada. Difere pelos tubérculos pronotais maiores e mais projetados e pela pontuação dos élitros inaparente mesmo na metade anterior. Em $R$. melzeri os tubérculos pronotais são menos desenvolvidos e a pontuação elitral é bem aparente e densa na metade anterior dos élitros. Das demais espécies do gênero, distingue-se pelos élitros unicolores.

\section{Ataxia parva sp. nov.}

Figura 7

Etimologia. Latim, parva = pequeno, curto; alusivo ao comprimento do corpo.

Descrição. Tegumento castanho-escuro revestido por pubescência amarelo-acinzentada, densa, intercalada por cerdas acastanhadas. Lobos oculares superiores com três fileiras de omatídios, separados entre si por mais do que o triplo da largura de um lobo. Lobos oculares inferiores mais longos que as genas. Antenas não alcançam o ápice dos élitros. Antenômeros III-XI castanho-avermelhados com anel apical escurecido.

Protórax com espículo lateral reduzido e pequeno tubérculo próximo da margem anterior. Pronoto sem tubérculos; inteiramente revestido pela pubescência, exceto em duas pequenas áreas circulares, próximas a base, glabras. Escutelo e terço basal da sutura com pubescência acastanhada, curta. Processo mesosternal truncado anteriormente.

Élitros com pubescência amarelada, longa, densa, uniforme e, junto às margens laterais, mais acinzentada, curta; pontuação inaparente. Ápices elitrais com espinho curto no ângulo marginal.

Face ventral com mesmo padrão de pubescência dos élitros, levemente mais acinzentada no centro do pro- e mesosterno; sem pontos contrastantes. Último urosternito da fêmea deprimido no meio da borda apical. Metatíbias com pontos pouco contrastantes.

Dimensôes em mm. Comprimento total, 7,3; comprimento do protórax, 1,4; maior largura do protórax, 1,6; comprimento do élitro, 5,4; largura umeral, 1,9.

Material-tipo. Holótipo fêmea, BRASIL, Paraíba: São João do Cariri, 15.IV.2006, M. A. B. de Gusmão (MZSP).

Discussão. Ataxia parva sp. nov. apresenta processo mesosternal truncado, espinho curto no ângulo marginal dos élitros e pubescência corporal amarelada como em $A$. albisetosa Breuning, 1940, A cylindrica Breuning, 1940, e $A$. uniformis Fisher, 1926. Distingue-se de $A$. albisetosa por não ter pelos e cílios brancos entremeados na pubescência elitral; de $A$. cylindrica e $A$. uniformis pela pequena dimensão $(7 \mathrm{~mm}$ de comprimento) e pela ausência de pontos contrastantes no pronoto e nos élitros. 


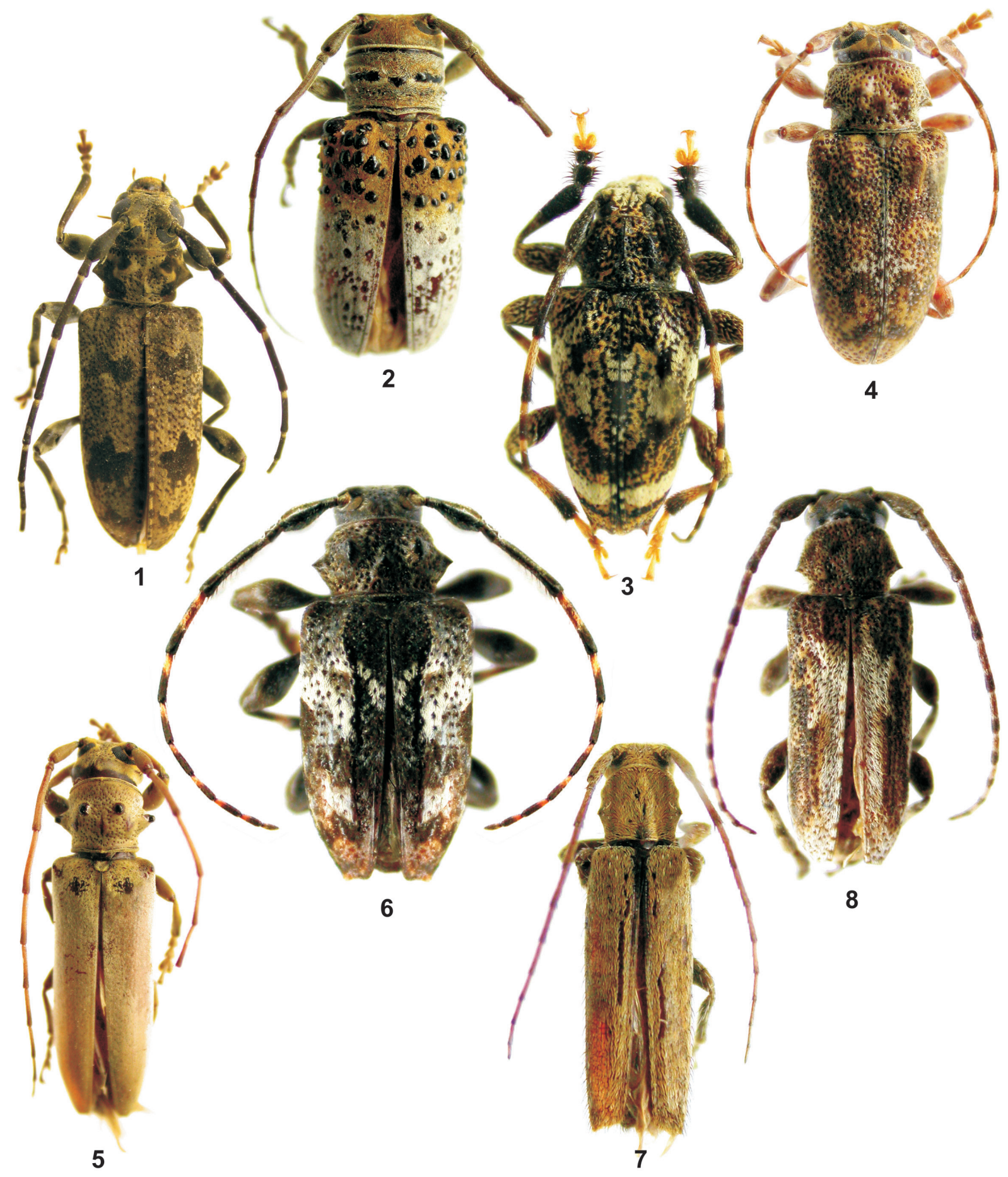

Figuras 1-8 - Habitus. 1. Psapharochrus rondonensis sp. nov., holótipo fêmea, comprimento $20,5 \mathrm{~mm}$; . Oncideres disiunctus sp. nov., holótipo fêmea, comprimento 13,3 mm; 3. Psapharochrus inaequalis sp. nov., holótipo macho, comprimento 9,0 mm; 4. Punctozotroctes tuberculatus sp. nov., holótipo macho, comprimento 9,5 mm; 5. Rhaphiptera apeara sp. nov., holótipo macho, comprimento 19,4 mm; 6 . Psapharochrus irumus sp. nov., holótipo macho, comprimento 10,3 mm; 7. Ataxia parva sp. nov., holótipo fêmea, comprimento 7,3 mm; 8. Meridiotroctes truncata sp. nov., holótipo macho, comprimento 9,7 mm. 


\section{ONCIDERINI}

\section{Oncideres disiunctus sp. nov.}

Figura 2

Oncideres fulvoguttata Galileo \& Martins, 2007:68, fig. 3 non Dillon \& Dillon, 1946:356, est.14, fig.4.

Etimologia. Latim, disiunctus = separado, afastado.

Descrição. Cabeça com pubescência alaranjada mais concentrada no lado interno dos olhos e ao redor deles. Antenas com pubescência acastanhada.

Pronoto com cinco manchas glabras; superfície pronotal coberta por pubescência mesclada de branco e alaranjado.

Terço basal dos élitros coberto por pubescência alaranjada e o restante da superfície com pubescência branca. Base dos élitros com grânulos grandes, prolongam-se até atrás do meio em grânulos mais esparsos e menores, contrastantes. Terço apical dos élitros, separado da região central por uma faixa estreita, transversal de manchas pequenas; com linhas longitudinais, bifurcadas.

Fêmures com pubescência castanho-esbranquiçada nas clavas. Lados do metasterno com pubescência branca, densa; restante da face ventral do corpo com pubescência branca.

Dimensóes em mm. Comprimento total, 13,3; comprimento do protórax, 2,6; maior largura do protórax, 4,0; comprimento do élitro, 9,6; largura umeral, 5,4.

Material-tipo. Holótipo fêmea, BRASIL, Amazonas: Manaus (Reserva Ducke, 26 km N), 23.III.1996, J. C. Hurtado col., em choque de inseticida em Eschweilera pseudecolorans (INPA).

Discussão. Oncideres disiunctus sp. nov. distingue-se de O. fulvoguttata Dillon \& Dillon, 1946 pela ausência de manchas pequenas alaranjadas no terço apical dos élitros. Em O. fulvoguttata o terço apical dos élitros tem inúmeras manchas alaranjadas.

Difere de O. pretiosa Martins \& Galileo, 1990 também de Manaus (Amazonas) pelos grânulos separados e prolongados até o meio. Em $O$. pretiosa os grânulos da base são numerosos, próximos e, às vezes, confluentes restritos no quarto basal dos élitros.

\section{AGRADECIMENTOS}

Aos curadores Freddy Bravo (UEFS) e James Wappes, American Coleoptera Museum, San Antonio, EUA, ao coletor José Camilo Hurtado (INPA) que nos remeteram material para estudo; a Eleandro Moysés (Bolsista IC/CNPq/Museu de Ciências Naturais, Fundação Zoobotânica do Rio Grande do Sul) pela execução das imagens digitalizadas.

\section{BIBLIOGRAFIA CITADA}

Breuning, S. 1961. Révision des Pteropliini (Col., Cerambycidae). Pesquisas, (5)9: 5-60.

Machado, V.S. \& Monné, M. L. 2009. Synopsis of the genus Meridiotroctes Martins \& Galileo (Coleoptera: Cerambycidae). Zootaxa, 2261: 66-68.

Martins, U. R. \& Galileo, M. H. M. 2007. Novos táxons e notas sobre Acanthoderini (Cerambycidae, Lamiinae) com artículo III dos palpos labiais truncado. Papéis Avulsos de Zoologia, 47(16): 187-190.

Martins, U. R.; Galileo, M. H. M. \& Limeira-de-Oliveira, F. 2009. Cerambycidae (Coleoptera) do estado do Maranhão, Brasil. Papéis Avulsos de Zoologia, 49(19): 229-247.

Tavakilian, G. L.; Dallens, P. H. \& Toroult, J. 2007. Les Raphiptera Audinet-Serville, 1835, en Guyane et description d'un nouveau genre affine (Coleoptera, Cerambycidae, Lamiinae, Pteropliini). Les Cahiers Magellanes, 72: 1-19.

Tavakilian, G. L. \& Néouze, G. L. 2007. Le genre Ozotroctes Bates: nouvelles espèces et nouveaux genres apparentés d'Acanthoderini (Coleoptera, Cerambycidae, Lamiinae). Coléoptères, 13(1): 1-24.

Recebido em 29/01/2010

Aceito em 26/03/2010 
